\title{
Situational Nutritional Analysis of Idumishmi Tribes of Arunachal Pradesh, North-East India
}

\author{
Lauri Wright, Palak Gupta* \\ University of South Florida, United States \\ *Corresponding author: palak.gupta@flhealth.gov
}

\begin{abstract}
The studies on tribal population is limited. Therefore, this study investigated the dietary patterns and nutritional health of the Mishmi tribespeople; and evaluated the cultural beliefs surrounding food and their potential impact on nutritional health. It also explored the degree of nutrition transition among the tribal community. Qualitative data collection on four relevant health and nutrition topics was completed using diet recalls, anthropometry, focus groups and key informant interviews. Trained moderators conducted interviews using a pre-tested, structured interview schedule. Focus group interviews and diet recalls were noted, transcribed and translated. Standard analysis was done using different relevant software. It was found that tribal people were consuming a two-meal pattern diet with high carbohydrate, low fat content, poor in vitamin A, thiamin, riboflavin, niacin, B12, vitamin C, calcium, and iron. Anthropometric analysis showed one-fourth of children 2-9 year old were underweight and 7\% were stunted. Many cultural beliefs existed around foods avoided during pregnancy such as papaya, pineapple, twin-fruit, and iron supplementation. Colostrum was considered as bad milk. Appropriate age for introduction of complementary foods was not clear to the mothers. Chronic diseases such as diabetes and hypertension were perceived to be high among tribal people. Based on their dietary patterns, physical activity and health status, Idu Mishmi tribes' appears to be in pattern 3 of the nutrition transition: characterized by labor-intensive work; starchy, low variety, low fat diet; nutritional inadequacies and an absence of obesity. Thus, it can be concluded that little nutrition transition was found among the Idu Mishmi tribe but there were several potentially harmful dietary practices and beliefs followed. Thus, nutrition education is key to increase intake of micronutrients rich food, types and amount of food required by pregnant women, importance of colostrum for infant's health, timely introduction of complementary foods for infants, and reinforce healthy dietary and lifestyle choices to prevent obesity and development of non-communicable, chronic diseases.
\end{abstract}

Keywords: health, nutrition, Idu Mishmi, tribes, India, arunachal pradesh

Cite This Article: Lauri Wright, and Palak Gupta, "Situational Nutritional Analysis of Idumishmi Tribes of Arunachal Pradesh, North-East India.” Journal of Food Security, vol. 5, no. 4 (2017): 113-119. doi: 10.12691/jfs5-4-1.

\section{Introduction}

Nutrition is the basic human need and a prerequisite to a healthy life. A proper diet is essential from the very early stages of life for proper growth, development and to remain active [14]. India occupies a hot spot in the global map of childhood stunting as 61 million (37\%) of the 165 million stunted children aged under five years globally are Indian children [30]. According to recent National Family Health Survey (International Institute for Population Sciences and Macro International 2005), 35.6\% of women have a low BMI, $30 \%$ of adults suffer from moderate and severe grades of protein-calorie malnutrition as judged by anthropometric indicators. National Nutrition Monitoring Bureau [15] survey reported that chronic energy deficiency (BMI< 18.5) among tribal adult women is $49 \%$. India, being a country in developmental transition, faces the dual burden of under-nutrition as well as over-nutrition. Modernization, urbanization, economic development, and increased wealth lead to predictable shifts in diet, referred to as the "nutrition transition" [17]. As developing societies like India industrialize and urbanize, and as standards of living continue to rise, weight gain and obesity are beginning to pose a growing threat to the health of the citizens. According to the World Health Organization's (WHO) global database, India has a preschool childhood obesity prevalence of about $1 \%$ [34]. The use of the commonly used indicator of pre-school childhood malnutrition (weight-for-height) may also exaggerate the problem of obesity among stunted children [18]. Repeated episodes of malnutrition, followed by nutritional rehabilitation, are known to alter body composition and increase the risk of obesity [24].

While nutrition outcomes across India are poor, they are typically worse in regions which the Government of India (GoI) refers to as 'Tribal and Backward Areas' (TABAs) [28]. The indigenous peoples of India are often called Adivasis or Scheduled Tribes. India is a home to more than half the world's tribal population. India's 'indigenous peoples' number about 104 million and account for $8.6 \%$ of the overall population, which is four 
times larger than that of the population of Australia. Most are concentrated in a third of India's 640 districts and, the vast majority, over 94 million, lives in rural areas [3]. Geographically, ST populations mostly reside in the states of Madhya Pradesh, Maharashtra, Odisha, Gujarat, Rajasthan, Jharkhand, Chhattisgarh, Arunachal Pradesh, West Bengal, Karnataka, Assam and Meghalaya. They are amongst the lowest income citizens in the country, highly dependent on the forests and other natural resources of the enclaves into which they have been pushed over time.

Arunachal Pradesh is one of the North eastern provinces of India bordering Tibet, Bhutan, China and Myanmar. It is situated on the Great Eastern Himalayan Mountain range and recognized as one of the Mega Biodiversity hot spots of the world [13]. More than 25 different group of tribal population are living in this hill state from time immemorial. Each of the tribes has a unique tradition of culture and lifestyle occupying different geographical regions [26].

Tribal people are amongst the poorest and most marginalized population groups experiencing extreme levels of health deprivation [32]. Although several studies on maternal health and nutritional status have been carried out in India among the general population, there is a dearth of information pertaining to the health and nutritional status among young children and women in tribal populations. Given the fact that every twelfth woman in India belongs to a tribal community, improving their health status becomes an important developmental goal. Improving tribal people's health, especially women's health, as well as eliminating the tribal / non- tribal health divide requires the addressing of the knowledge gap related to understanding the patterns of tribal health deprivation.

The purposes of the exploratory research reported in the present paper were to: investigate the dietary patterns and nutritional health of the Mishmi tribespeople; evaluate the cultural beliefs surrounding food and their potential impact on nutritional health; and explore the degree of nutrition transition among the tribal community.

\section{Methodology}

The present study was conducted over the period of two months from February to March 2016 in Arunachal Pradesh among Idu Mishing tribe. Ethical approval for the study was obtained from the University Institutional Review Board.

\subsection{Research Setting}

Research was conducted in the Idu Mishmi tribes in the Arunachal Pradesh state of Northeast India. The Mishmis occupy the northeastern tip of the central Arunachal Pradesh in Upper and Lower Dibang Valley, Lohit and Anjaw Districts. The Mishmi community can be broadly divided into three major groups. These are called Idus or Chulikatas, Digarus or Taroan and Mijus or Kaman. Divisions are being made on the basis of different geographical allocation of these Mishmi tribes, rather than any kind of racial discrepancies. In fact all these three tribal groups fall into the Mishmi as a whole. The Idu
Mishmi tribes are mainly found in the Upper Dibang Valley district and also in a few parts of the northern parts of Lohit district of Arunachal. Agriculture is the main source of income among Mishmi tribe [7]. Timber trading is another source of income. Their occupation is supplemented by wage labor, shop keeping and small scale business. Women are involved in weaving and crafting products such as blouses and coats. Rice is the staple food. They relish pork meat along with Apong (rice beer) in all their ethnic festivals [2]. The Mishing people are very fond of green-leafy vegetables that they grow in their kitchen garden [1]. Usually, the Mishing claim to be Hindus by religion, but at the same time, they observe all their ethnic traditional rituals and festivals. In the course of cultural evolution, their religions, along with their traditional belief, Vaishnavism and Christianity have become part of their life.

\subsection{Data Collection and Analysis}

The present study was descriptive and exploratory in nature and our universe was Indu-mishmi population. The following broad areas were explored in the present study.

Dietary Patterns. Dietary data was collected in three phases. Phase one involved key informant interviews as an initial exploratory exercise. In phase two, unstructured pilot observations of meals in households were conducted. The final phase involved 24-hour food recalls with individuals. Dietary data was analyzed by a trained registered dietitian using Food Processor, copyright 2014.

Assessment of Nutritional Health. To assess the nutritional health of children, weight and height were measured using standard anthropometric techniques. The children were weighed with a digital electronic scale sensitive to the nearest $100 \mathrm{~g}$; and height was measured using stadiometer sensitive to nearest $0.1 \mathrm{~cm}$. Children's heights and weights were then assessed using WHO Child Growth Standards (WHO, 2006) of height-for-age z-scores (HAZ) and weight-for-age z-scores (WAZ). HAZ is an indicator of height status. Stunting is defined as HAZ > -2 SD of the WHO Child Growth Standards median. Stunting is an indicator of chronic or long term nutritional status of the children. WAZ measures weight status. Underweight is defined as WAZ $>-2$ Standard Deviation (SD) of the WHO Child Growth Standards median. For anthropological assessments, WHO AnthroPlus software was used. Age was calculated to the precise day by subtracting the date of birth from the date of examination. The $\mathrm{z}$ score values for height-, weight- and BMI-for-age relative to the WHO 2007 reference were calculated using WHO AnthroPlus (WHO, 2006).

Cultural Beliefs. To understand the cultural food practices, focus groups and interviews with key leaders were conducted. The focus group using a semi-structured interview schedule format was chosen due to the transcultural basis of the research as the population belonged to a different cultural group to the researchers. Themes were derived through iterative readings and discussion of the expanded notes by both authors. For interviews, Open questions were posed to the group and interviews were recorded and later transcribed.

Nutritional Transition. Trends in dietary intake, activity patterns, urbanization, and disease were assessed and 
compared to Popkin's patterns of the nutrition transition (Popkin, 2006). Popkin divide the nutrition transition into five patterns. Pattern 1, Hunter Gatherer, is characterized by individuals living highly active lifestyles, hunting for food. Diets are typically rich in iberous plants and protein from wild animals. Pattern 2, Early Agriculture, is characterized by common famine, decreased individual growth and body fat. Pattern 3, End of Famine, is where famine recedes as income rises and nutrition improves. Pattern 4, Overeating, Obesity-related Diseases. In this pattern, income continues to rise, individuals have access to an abundance of high-calorie foods, and they become less active, leading to increases in obesity and obesityrelated chronic diseases. Pattern 5, Behavior Change, is characterized by individuals and communities changing behaviors to prevent the increasing rates of obesity and obesity-related chronic diseases.

\section{Results}

\subsection{Dietary Patterns and Nutrition Adequacy}

Dietary Patterns. The common dietary pattern was determined from interviews with 8 key informants, observation of five household meals and 24-hour food recalls with 13 adults. The dietary pattern consisted of 2 meals each day. The foods consumed were the same for each meal; typically, white rice which was not enriched, lentils, potatoes and green leafy vegetables. Meat was consumed on average $2-3$ times a week and was generally 3-4 ounce portions. The tribespeople drank tea flavored with whole milk and sugar twice day. Adults drank rice beer every day.

Nutrient content. Table 1 contains the results of the nutrient analysis of the common dietary pattern. The diet was found to be adequate in calories for moderate to heavy labor people. The protein intake was also adequate, averaging $1 \mathrm{~g}$ of protein $/ \mathrm{kg}$. As seen in Figure 1 , the calorie distribution of macronutrient demonstrates a high carbohydrate content (71\%), low fat (14\%) diet. Analysis of micronutrients found the diet to be adequate in B6 and folate. The diet was marginal in fiber and zinc. There were significantly low intakes of vitamin A, thiamin, riboflavin, niacin, B12, vitamin $\mathrm{C}$, calcium, and iron.

Table 1. Nutrient Intake of the sample $(n=13)$

\begin{tabular}{lcc}
\hline Nutrient & Value & \% Recommended \\
\hline Calories & 2285.79 & - \\
Protein (g) & 54.18 & - \\
Carbohydrates (g) & 406.18 & - \\
Sugars (g) & 74.46 & - \\
Dietary Fiber (g) & 20.14 & $66.10 \%$ \\
Fat (g) & 36.20 & - \\
Vitamin A (RAE) & 73.76 & $10.54 \%$ \\
Vitamin B1 (mg) & 0.67 & $61.19 \%$ \\
Vitamin B2 (mg) & 0.46 & $41.63 \%$ \\
Vitamin B3 (mg) & 9.49 & $67.77 \%$ \\
Vitamin B6 (mg) & 1.33 & $102.52 \%$ \\
Vitamin B12 (mcg) & 0.09 & $3.93 \%$ \\
Vitamin C (mg) & 36.22 & $48.29 \%$ \\
Vitamin D (mcg) & 0 & $0 \%$ \\
Folate (mcg) & 435.66 & $108.91 \%$ \\
Calcium (mg) & 283.97 & $28.40 \%$ \\
Fluoride (mg) & 0.21 & $7.14 \%$ \\
Iron (mg) & 9.91 & $55.06 \%$ \\
Zinc (mg) & 6.99 & $87.41 \%$ \\
\hline
\end{tabular}

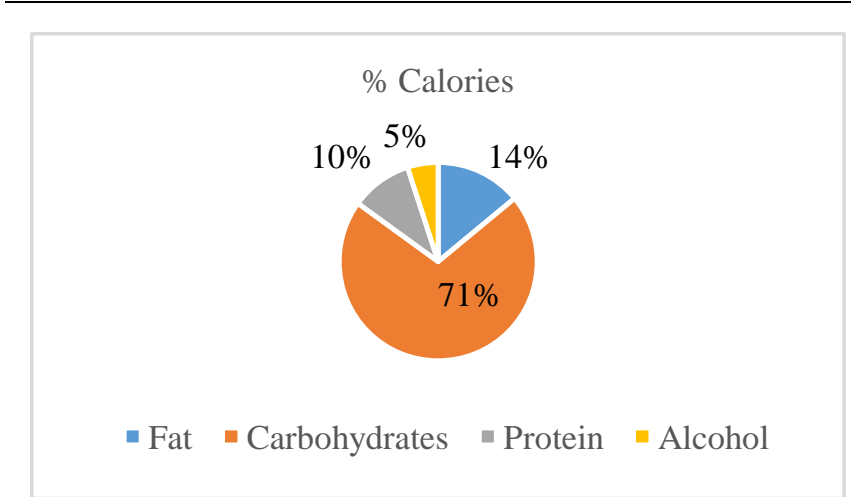

Figure 1. Distribution of Calories from Macronutrients (n=13)

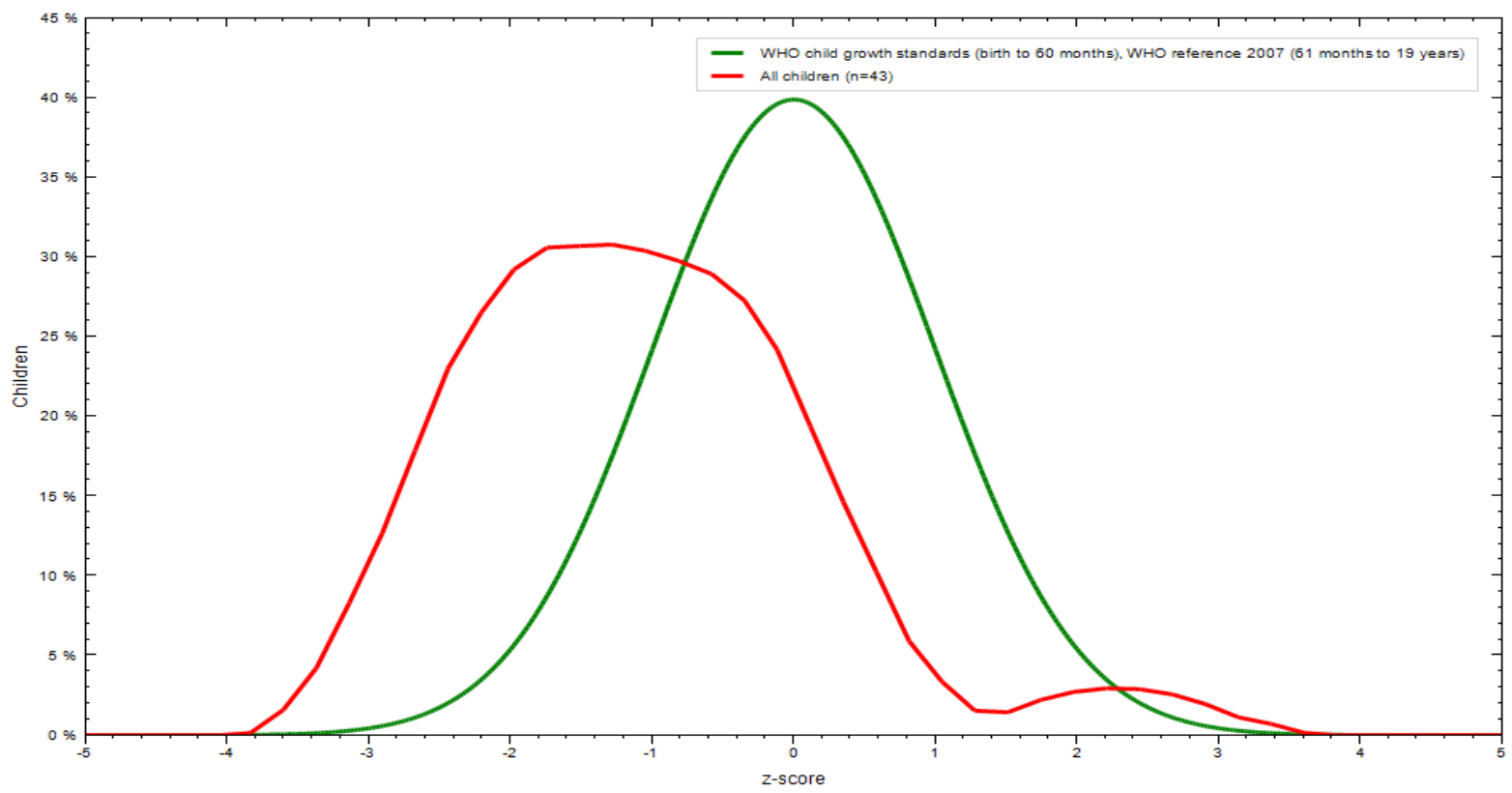

Figure 2. Gender-wise weight-for-age distribution for Sample children $(n=43)$ 
Table 2. Anthropometric profile of children (column \%)

\begin{tabular}{|c|c|c|c|}
\hline & Girls \% (n=19) & Boys \% $(n=24)$ & Total $\%(n=43)$ \\
\hline \multicolumn{4}{|l|}{ BMI-for-age } \\
\hline Thin ( $\geq-3 S D)$ & 10.5 & 25.0 & 18.6 \\
\hline Severely thin ( $<-3 \mathrm{SD}$ to $\geq-2 \mathrm{SD}$ ) & 10.5 & - & 4.6 \\
\hline Normal $(<-1 \mathrm{SD}$ to $<1 \mathrm{SD})$ & 78.9 & 75.0 & 76.8 \\
\hline \multicolumn{4}{|l|}{ Weight for age } \\
\hline Underweight ( $<-3 \mathrm{SD}$ to $\geq-2 \mathrm{SD}$ ) & 26.3 & 20.8 & 23.3 \\
\hline Normal (<-2SD) & 73.7 & 79.2 & 76.7 \\
\hline \multicolumn{4}{|l|}{ Height for age } \\
\hline Stunting ( $\geq-3 S D)$ & 10.5 & 4.2 & 7.0 \\
\hline Severely Stunted ( $<-3 \mathrm{SD}$ to $\geq-2 \mathrm{SD}$ ) & - & 8.3 & 4.6 \\
\hline Normal $(<-1 \mathrm{SD}$ to $<1 \mathrm{SD})$ & 89.5 & 87.5 & 88.4 \\
\hline
\end{tabular}

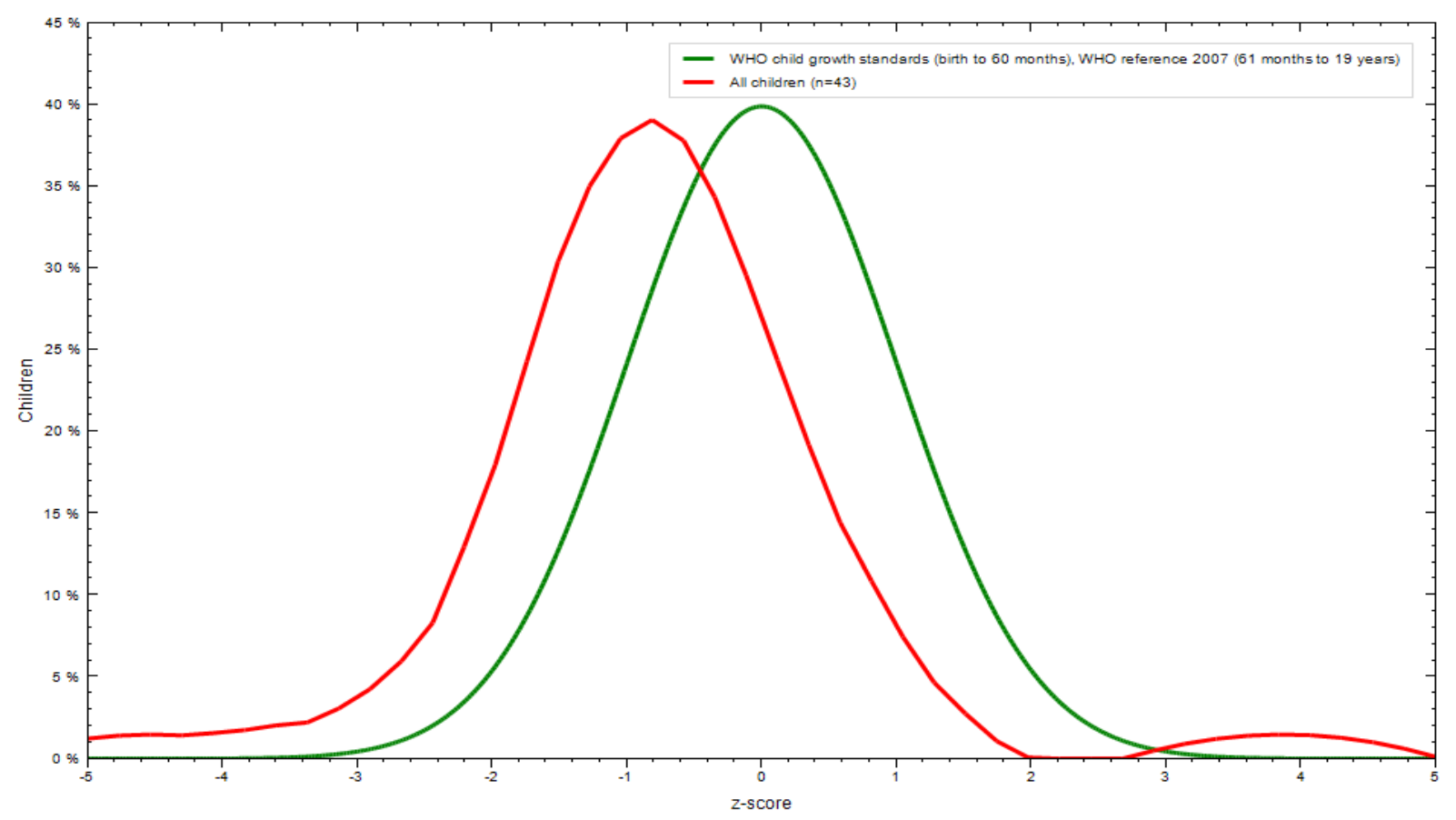

Figure 3. Gender-wise height-for-age distribution for Sample children $(n=43)$

Children's Growth Assessment. A total of 43 children were assessed for growth patterns as an indicator of nutritional health (Table 2). The children ranged in age from 2 to 9 years old. Fifty-six percent of the children were males and $44 \%$ were females. Based on the CDC growth curves for BMI, 38\% of children were categorized as underweight, 56\% were categorized as normal weight, $5 \%$ were categorized as overweight, while no children were categorized as obese.

Data was analyzed to understand prevalence of underweight among tribal children. From Figure 2 it can be observed that the distribution of the children's weights was skewed towards the left, indicating more number of children were in the range below normal. In the present study, $23.25 \%$ of total children were underweight (Table 2); however, none of the study sample children were found to be severely underweight.

When children were categorized per gender (Table 2), more girls (26.3\%) were underweight than boys (20.8\%). The distribution of the heights was found to be skewed towards the left, indicating more children was stunted than the normal reference population (Figure 3). In the sample, $7 \%$ of children were stunted and $4.6 \%$ were severely stunted. When seen across gender (Table 2), girls (10.5\%) experienced less stunting than boys (12.5\%). Almost 5\% of the boys were severely stunted while no girl was severely stunted.

\subsection{Cultural Beliefs Surrounding Foods and Impact on Nutritional Health}

A total of three focus groups were conducted to determine cultural beliefs: 1) medical professionals, 2) key tribal leaders, and 3) school faculty. Interviews were also conducted with 8 pregnant women and 5 parents of school children. Results from the thematic analysis of the focus group and interview notes are divided into two main areas: 1) cultural beliefs surrounding foods throughout the lifecycle; 2) cultural beliefs surrounding health and accessing healthcare. Emergent themes are presented for both areas.

\subsection{Cultural Beliefs Surrounding Foods throughout the Lifecycle}

Pregnancy. Some dietary rules exist for pregnant women. Common foods excluded during pregnancy include eggplant and papaya. Mothers and grandmothers tell pregnant women to avoid these foods as they are thought to cause miscarriages. They further believe that 
papaya can cause premature lactation. As such, they are not allowed to eat papaya during pregnancy but are told to increase their intake during lactation. Some women also believed eating pineapple during pregnancy can cause miscarriage. Consuming banana with twin fruit inside is thought to cause women to have twins so they avoid eating banana before and during pregnancy. There is a popular belief that women should not sell fruits and eggs during the pregnancy. The reason behind this belief is not known but since it is a popular beliefs, women do not sell them during pregnancy. Overall, pregnant women avoid taking the prenatal iron supplement because it is believed to cause babies to be born larger. Women are allowed to consume diet beer during pregnancy as it is believed to have medicinal value. However, if a breastfed child has diarrhea, the mother is advised to avoid rice beer.

Infants. The popular practice of the community is to not give colostrum to the baby and discard it. Colostrum is considered 'bad milk' or 'dirty milk' and hence not good for the baby. Elder women tell mothers to introduce complementary foods only after 1 year of age. We found that many mothers are disregarding this cultural belief and introducing solids earlier.

Children. Based on interviews and focus groups, no difference were found in feeding practices between genders. Children overall were given extra food such as milk and meat to help them grow.

Adults. Men are allowed to catch, prepare and eat game meat while women are not allowed to consume game meat or meat from four-legged animals. The meat restrictions end for women after menopause. After men consume game meat, they must stay away from women for 5 days.

\subsection{Cultural Beliefs Surrounding Health}

Health Issues. In homes, there was no refrigeration system for safely storing leftover foods. Smoking of meats is the most common method to preserve raw meats but meat is often left out at room temperature for prolonged period before smoking. At the market, raw meat is left out in open displays all day. Many homes have open sanitation system. Water is stored in plastic buckets without cover for long periods and is used without treatment. Water is only boiled for consumption by very young children. All the homes are stilts with animals such as pigs and chickens living below. Leftover food and bodily waste drops down to the animals for consumption.

\subsection{Nutrition Transition}

Nutrition transition was assessed using trends in dietary intake, activity patterns, urbanization, and disease patterns. The food consumption patterns were consistent with the traditional staple foods of the Idu Mishmi tribe. There was no globalized food available and no evidence of changing eating patterns. Additionally, the diet is not varied and is subject to scarcity during monsoon season. The economic base of the tribespeople is still primarily agricultural and hunting. As such, the physical activity patterns are moderate to vigorous. Additionally, there are no televisions or computers to decrease the activity patterns. As seen with the children's weights and themes in the focus groups with physicians, the health concerns are still primarily undernutrition and infectious diseases. There was little evidence of obesity and diet-related, noncommunicable diseases. Based on Popkin's stages of the nutrition transition, the Idu Mishmi tribe appears to be in pattern 3 of the nutrition transition which is characterized by labor-intensive work; starchy, low variety, low fat diet; nutritional inadequacies and an absence of obesity.

\section{Discussion}

The present study sought to describe the dietary patterns and nutrition health of the Mishmi tribespeople in Northeastern India. In regards to the diet and nutritional adequacy, the diet was found to be high in carbohydrates but deficient in thiamin, niacin, and riboflavin. This is due to the fact that the rice is not enriched with the B-vitamins lost during milling. The green, leafy vegetable intake helped in meeting the folate needs and moderate amounts of fiber. The diet however was low in vitamin A. This finding was reinforced by the xerophthalmia observed during physical examination of the children. One medical issue reported by the physicians interviewed in the focus group was anemia. As seen in the nutrient analysis, the average iron intake was only 55\% of recommended intake. The sources of iron in the diet are plant foods or non-heme iron. While vitamin $\mathrm{C}$ enhances the absorption of non-heme iron, the vitamin $\mathrm{C}$ intake of the Mishmi tribe was also low. Finally, calcium intake was found to be very low in the diets. Observation of older women in the tribes and a theme reported in the focus group with key leaders was the commonality of curved spines in the older women, often associated with osteoporosis. Because of the micronutrient deficiencies found, nutrition education is indicated focusing on locally available foods or preparation methods to enhance nutrient value. One example would be to encourage the tribespeople not to mill the rice as the whole grain is a valuable source of iron, thiamin, niacin, and riboflavin.

To complement the information gathered on dietary patterns and nutrient adequacy, children's growth patterns was also investigated. Reports have shown the childhood stunting rate in India overall is $37 \%$ for children under 5 . For the Mishmi children, we found a significantly lower stunting rate at $11.6 \%$. The prevalence of stunting was found to be less prevalent than the $50 \%$ reported for the Kamar children of Chhattisgarh [11], 54\% for the Oraon of North Bengal [12], the 54\% reported in the tribal children of Bihar [20], and the $45.8 \%$ found in children of West Bengal [27]. The present study found the incidence of underweight children to be $23.3 \%$ which distinctly lower than $61.1 \%$ found among tribal children of Madhya Pradesh [21] and the 60\% found among children from Rajasthan [25]. The finding of lower prevalence of undernutrition is consistent with the overall nutrient analysis results of adequate calorie and protein intake. In this primarily agriculture community, a lack of food access was not reported in focus groups which would be protective against stunting and malnutrition. Further, it was reported in focus groups that children, regardless of gender, were given extra portions of food including fish and milk. Though only a small sample, the relatively low rates of stunting in children seems to indicate general 
nutritional adequacy and health for the children of the tribe.

The cultural beliefs found surrounding food and health was similar to the literature on tribes in different states of India. Women from tribes of Gadaba and Konda Dora of Andhra Pradesh also discard colostrum partially or completely [4]. They do not consider colostrum good for babies and it is thought to be impure and heavy to digest. Studies have shown has shown that initiation of breastfeeding within the first hour of birth could reduce neonatal mortality by $22 \%$ [9]. Thus it is very important to educate women and the elders of the community (as they have strong influence on the mothers) on importance of colostrum. Also in the present study, recommended age for introducing complementary feeding was not known by the mothers. Poor complementary feeding practices means that many children continue to be vulnerable to irreversible outcomes of stunting, poor cognitive development, and significantly increased risk of infectious diseases leading to gastroenteritis, diarrhea and acute respiratory infection $[6,23,33]$. Exclusive breastfeeding for six months followed by timely initiation of appropriate complementary feeding with continued breastfeeding for the first year of life could avert $13 \%$ (1.3 million) of the more than 10 million deaths among children under 5 every year [19].

Alcoholism, tobacco and smoking, even during pregnancy, is culturally accepted among tribals and often used as a way to avoid meals [10]. These findings have been corroborated by UNICEF report [31] on tribal children. The Mishing tribe women reported consuming rice beer during pregnancy as well as during lactation. This has implications on the baby and can lead to miscarriages, stillbirths, premature labor, fetal alcohol spectrum disorder and fetal alcohol syndrome [22].

The process known as nutrition transition refers to major cyclical changes in the nutritional profile of human populations produced by modifications in both dietary and nutrient expenditure patterns and determined basically by interplay of economic, demographic, environmental and cultural changes occurring in the society [16]. India, along with many other countries in Asia, is experiencing the nutrition transition. One aim of this project was to see if the nutrition transition was being experienced among the Idu Mishmi tribe. The dietary pattern appeared relatively unchanged from the traditional diet of the Idu Mishmi tribe. The food consumption patterns are consistent with research on hunter-gatherer populations being high in carbohydrates and low in fat, especially saturated fat $[5,29]$. The tribe still experiences some famine during monsoon but improvements have been seen. Physical activity patterns have not changed as the economic base is still primarily agricultural and hunting. Health issues still seem related to maternal and child nutrient deficiencies and stunting with little evidence of obesity and obesity-related diseases. In the future as tribespeople move from rural areas to villages, it is expected that more pronounced changes in dietary and activity patterns will occur. As such, education will be needed on healthy lifestyle choices to prevent the obesity and obesity-related diseases such as diabetes often associated with the nutrition transition.

\section{Conclusions and Recommendations}

In conclusion, little nutrition transition was found among the Idu Mishmi tribe but there were several potentially harmful dietary practices and beliefs followed. Thus, nutrition education is key to increase intake of micronutrients rich food, types and amount of food required by pregnant women, importance of colostrum for infant's health, timely introduction of complementary foods for infants, and reinforce healthy dietary and lifestyle choices to prevent obesity and development of non-communicable, chronic diseases.

\section{References}

[1] Basu, D., Gajbhiye, S. 2004. Nutritional status of the Mishing of Sonitpur, Assam. In Nutritional Status of Indian Population: North east India, eds. K.K. Bhattacharya, S.S. Dutta, D. Choudhury, and D. Tyagi, 21-32 Kolkata: Anthropological Survey of India.

[2] Bordoloi, B.N., Sharma Thakur, G.C., Saikia, M.C. 1987. Tribes of Assam Part-I. Published by Bordoloi BN, Tribal research Institute. Assam, India.

[3] Chandramouli, C. 2013. Release of Primary Census Abstract Data Highlights, Census of India 2011, Registrar General and Census Commissioner of India, Ministry of Home Affairs. New Delhi, India. http://idsn.org/fileadmin/user_folder/pdf/New_files/India/2013/IN DIA_CENSUS_ABSTRACT-2011-Data_on_SCSTs.pdf (accessed June 10, 2016).

[4] Giridhar, L., Lakshmi, G. 2012. Practices regarding colostrums and pre-lacteals among gadaba and konda dora tribes of vizianagaram district. IOSR Journal of Parmacy 2 (5): 8-12.

[5] Harris, D.R. 1981. The prehistory of human subsistence: a speculative outline. In Food, Nutrition and Evolution: Food as an Environmental Factor in the Genesis of Human Variability, eds. D.N. Walcher, N. Kretchmer, 15-37. New York: Masson.

[6] Hop, L.T., Gross, R., Giay, T., Sastroamidjojo, S., Schultink, W., Lang, N.T. 2000. Premature complementary feeding is associated with poorer growth of Vietnamese children. Journal of Nutrition 130: 2683-2690.

[7] IndiaNetZone. 2014. Mishmi Tribe, Arunachal Pardesh. India. http://www.indianetzone.com/8/mishmi_tribe.htm (accessed June 5, 2016).

[8] International Institute for Population Sciences and Macro International. 2007. National Family Health Survey (NFHS-3), 2005-06. Mumbai, India.

[9] Karen, M., Edmond, C. Z., Maria, A., Quigley, S.A., Seth, O.A., Betty, R. 2006. Delayed Breastfeeding Initiation Increases Risk of Neonatal Mortality. Pediatrics 117: 380-386.

[10] Khanna, S. 2012. The interaction between tobacco use and oral health among tribes in central India. Tobacco Induced Diseases 10(1):16.

[11] Mitra, M., Kumar, P.V., Chakrabartti, S., Bharati, P. 2007. Nutritional status of Kamar tribal children in Chhattisgarh. Indian Journal of Pediatrics 74: 381-384.

[12] Mittal, P.C., Srivastava, S. 2006. Diet, nutritional status and food related traditions of Oraon tribes of New Mal (West Bengal), India. Rural Remote Health 6(1): 385.

[13] Myers, N., Mittermeier, R.A., Mittermeier, C.G., Fonseca, G.A.B., Kent, J. 2001. Biodiversity hotspots for conservation priorities. Nature 403: 853-858.

[14] National Institute of Nutrition. 2010. Nutritive value of India Foods. Hyderabad, India.

[15] National Nutrition Monitoring Bureau. 2003. Prevalence of Micronutrient Deficiencies. Technical Report No.22. Hyderabad, India.

[16] Popkin, B.M. 1993. Nutritional patterns and transitions. Population Development Reviews 19: 138-57.

[17] Popkin, B.M. 2006. Global nutrition dynamics: The world is shifting rabidly toward a diet linked with non-communicable diseases. American Journal of Clinical Nutrition 84:289-298. 
[18] Popkin, B.M., Richards, M.K., Monteiro, C.A. 1996. Stunting is associated in children of four nations that are undergoing nutrition transition. Journal of Nutrition 126: 3009-16.

[19] Prieto, C.R., Cardenas, H., Croxatto, H.B. 1999. Variability of breast sucking, associated milk transfer and the duration of lactational amenorrhea. Journal of Reproduction and Fertililty 115: 193-200.

[20] Rao, T.V.R.K., Vijay, T. 2006. Malnutrition and anemia in tribal pediatric population of Purnia district (Bihar). Indian Pediatrics 43: 181-182.

[21] Rao, V.G., Yadav, R., Dolla, C.K., Kumar, S., Bhondeley, M.K. Ukey, M. 2005. Undernutrition and childhood morbidities among tribal preschool children. Indian Journal of Medical Research 122: 43-47.

[22] Royal college of Obstetrics and Gynecologist. 2015. Alcohol and pregnancy.

https://www.rcog.org.uk/globalassets/documents/patients/patientinformation-leaflets/pregnancy/pi-alcohol-and-pregnancy.pdf (accessed May 10, 2016)

[23] Saha, K.K., Frongillo, E.A., Alam, D.S., Ariffen, S.E., Persson, L.A., Rasmussen, K.M. 2008. Appropriate infant feeding practices result in better growth of infants and young children in rural Bangladesh. American Journal of Clinical Nutrition 87: 18521859.

[24] Shetty, P.S. 2000. Diet and life-style and chronic noncommunicable diseases: What determines the epidemic in developing societies? In Nutrition Research: Current Scenario and Future Trends, ed. K. Krishnaswami, 153-167. New Delhi: Oxford \& IBH Publishing Company.

[25] Singh, M.B., Fotedar R, Lakshminarayana J, Anand PK. 2006. Studies on the nutritional status of children aged 0-5 years in a drought-affected desert area of western Rajasthan, India. Public Health Nutrition 9: 961-967.
[26] Solanki, G.S. 2000. Socio-cultural and faunal diversity of Arunachal Pradesh. Himalayan Journal of Environmental Zoology 16 (2): 159-170.

[27] Som, S., Pal, M., Bhattacharya, B., Bharati, S., Bharati, P. 2006 Socioeconomic differentials in nutritional status of children in the states of West Bengal and Assam, India. Journal of Biosocial Science 38: 625-642.

[28] The World Bank. 2014. India: Food Security and Nutrition in Tribal Areas. Report No: ACS9269. India.

http://www-wds.worldbank.org/external/default/WDSContent Server/WDSP/IB/2014/07/07/000333037_20140707100520/Rend ered/PDF/ACS92690WP0P1309710Box385256B00PUBLIC0.pdf (accessed June 3, 2016).

[29] Truswell, A.S. 1977. Diet and nutrition of hunter-gathers. Elsevier: 213-26.

[30] UNICEF. 2013. Improving Child Nutrition: The achievable imperative for global progress. New York, United States of America.

[31] UNICEF. 2014. Nourishing India’s Tribal Children: The nutrition situation of children of India's scheduled tribes. New Delhi, India.

[32] Willis, R., Stephens, C. Nettleton, C. 2004. The Right to Health of Indigenous Peoples. Report of a conference held at the London School of Hygiene and Tropical Medicine. London, United Kingdom.

[33] WHO. 1987. Division of Family Health: The prevalence and duration of breastfeeding in urban population of Chandigarh during a decade. Indian Pediator. 24: 879-887.

[34] WHO. 2000. Obesity: Preventing and Managing the Global Epidemic. Report of a WHO consultation. WHO Technical Report Series No. 894. Geneva, Switzerland.

[35] WHO. 2009. WHO AnthroPlus for personal computers Manual Software for assessing growth of the world's children and adolescents. Geneva, Switzerland. http:/www.who.int/growthref/tools/en/ (accessed March 21, 2016). 